Relations industrielles

Industrial Relations

\title{
The Working Mother, A Survey of Problems and Programs in Nine Countries, by Alice H. Cook. Second edition revised, Ithaca, New York State School of Industrial and Labor Relations, Cornell University, 1978, 71 pp.
}

\section{Marie Lavigne}

Volume 36, numéro 2, 1981

URI : https://id.erudit.org/iderudit/029172ar

DOI : https://doi.org/10.7202/029172ar

Aller au sommaire du numéro

Éditeur(s)

Département des relations industrielles de l'Université Laval

ISSN

0034-379X (imprimé)

1703-8138 (numérique)

Découvrir la revue

Citer ce compte rendu

Lavigne, M. (1981). Compte rendu de [The Working Mother, A Survey of Problems and Programs in Nine Countries, by Alice H. Cook. Second edition revised, Ithaca, New York State School of Industrial and Labor Relations, Cornell University, 1978, 71 pp.] Relations industrielles / Industrial Relations, 36(2), 458-458. https://doi.org/10.7202/029172ar

Tous droits réservés (C Département des relations industrielles de l'Université Laval, 1981
Ce document est protégé par la loi sur le droit d'auteur. L'utilisation des services d'Érudit (y compris la reproduction) est assujettie à sa politique d'utilisation que vous pouvez consulter en ligne.

https://apropos.erudit.org/fr/usagers/politique-dutilisation/ 
The Working Mother, A Survey of Problems and Programs in Nine Countries, by Alice H. Cook. Second edition revised. Ithaca, New York State School of Industrial and Labor Relations, Cornell University, 1978, $71 \mathrm{pp}$.

The Working Mother de Alice H. Cook regroupe les observations d'une enquête menée dans neuf pays sur la situation des mères au travail. Première monographie d'une série portant sur les mères au travail à travers le monde, ce texte comprend non seulement la description des conditions de travail des femmes ayant des enfants, mais fait aussi l'inventaire et l'évaluation des législations, politiques et programmes sociaux développés pour les travailleuses, tant dans des pays du bloc de l'Est (Russie, Allemagne de l'Est et Roumanie) que dans des pays non communistes tels le Japon, l'Autriche, Israël, la Suède, l'Australie et l'Allemagne.

Il s'agit d'un tour d'horizon particulièrement serré et bien documenté des diverses questions relatives à la situation des mères au travail. L'auteur y traite des taux de participation au travail salarié, de la motivation à l'emploi, de l'âge des travailleuses, de l'éducation, de la ségrégation des emplois, de la discrimination salariale, du travail à temps partiel, de la garde des enfants, des législations du travail féminin et enfin du syndicalisme. Pour chacun de ces thèmes, A.H. Cook dégage les grandes tendances, établit les points de convergence et de divergence entre les divers pays et souligne les expériences novatrices, expériences qui sont autant de voies intéressantes pour résoudre les problèmes et besoins des mères au travail.

L'analyse de Cook diffère passablement des analyses traditionnelles sur le travail féminin. Prenant pour point de départ que la participation croissante à la main-d'oeuvre des femmes mariées et des mères est un changement structurel du marché du travail, le phénomène «mère au travail» n'est pas traité de façon marginale, mais bien comme une caractéristique fondamentale de la maind'oeuvre féminine. Parce que les interruptions dues aux grossesses, à la maternité et au soin des enfants ne signifient plus un retrait définitif du marché du travail, elles déterminent donc un cyle de vie de travail différent pour les femmes. Actuellement, l'organisation du travail, autant à l'Est qu'à l'Ouest, est modelée sur les caractéristiques de la main-d'oeuvre masculine. Les femmes dont le rythme de travail est surtout basé sur l'alternance famille/travail, sont nécessairement pénalisées et conséquemment sont des travailleuses de seconde zone.

Rejetant d'emblée l'optique volontariste préconisant que la femme qui veut être égale peut le devenir, Cook insiste sur l'universalité et la dimension collective des problèmes des mères au travail. L'éventail des problèmes est tel, que pour les solutionner il est nécessaire de concevoir une politique d'ensemble de la main-d'oeuvre féminine, politique articulant les interventions concernant le marché du travail, les programmes sociaux et l'éducation. Jusqu'à maintenant, affirme Cook, la plupart des pays se sont contentés de légiférer à la pièce, ont établi des politiques inefficaces, non-intégrées, voire contradictoires. Seule la Suède échapperait à ce noir bilan de l'intervention étatique.

Cook croit cependant que le marché du travail peut s'adapter au rythme propre de la vie de travail des femmes, tout en ne les pénalisant pas. Ainsi, elle rappelle qu'aux lendemains de la deuxième guerre mondiale les États-Unis, reconnaissants des services rendus par les soldats, adoptèrent un "G.I. Bill of Rights", c'est-à-dire une loi prévoyant des mesures compensatoires pour les soldats démobilisés. Cook se demande alors pourquoi le retrait des femmes de la population active pour fournir des enfants à la nation, ne pourrait être considéré comme service à la nation. Pourquoi, demande-t-elle, ne pas songer à un "maternal bill of rights"?

Ce petit ouvrage, simple, clair, basé sur une abondante documentation, a le mérite de présenter un bilan de la situation des mères au travail tout en suscitant une réflexion intéressante sur l'actuelle organisation du travail dans les sociétés industrialisées.

\section{Marie LAVIGNE}

Conseil du statut de la femme Gouvernement du Québec 